\title{
Urinary Mercury Level, Neurobehavioral Performance, and Some Biochemical Markers in Children with Amalgam Restorations
}

\section{Merfat Oreby'1 , Nahed Abu Hamila², Tarek Al-nimer'3, Hanaa Hibishy4, Mohammed Seleem5}

\footnotetext{
${ }^{1}$ Departments of Forensic Medicine and Clinical Toxicology, Faculty of Medicine

${ }^{2}$ Department of Pedodontics, Faculty of dentistry

${ }^{3}$ Department of Physics, Faculty of Science

${ }^{4}$ Department of Medical Biochemistry, Faculty of Medicine

${ }^{5}$ Department of Neuropsychiatry, Faculty of Medicine
}

Tanta University, Tanta, Egypt

\begin{abstract}
At present, there is a lack of scientific evidence on toxicity from low-level mercury exposure in children. Despite the debate over the safety of dental amalgam fillings, amalgam is still widely used to restore posterior teeth in pediatric dentistry. Although, children could be at greater risk to harm from low-level exposure due to their developing nervous systems. Hence, this research was carried out to define some potential health effects from dental amalgam on children's health. Children were selected from those attending the Pedodontic clinic, Faculty of Dentistry, Tanta University. They were subjected to clinical examination, neurobehavioral and intelligence quotient (IQ) assessment, urinary mercury level, serum; malondialdehyde (MDA), reduced glutathione (GSH), zinc ( $\mathrm{Zn})$, and gamma amino butyric acid (GABA) measurement. The present study revealed that the mean urinary mercury level was significantly higher in the amalgam group $(8.15+0.99 \mu \mathrm{g} / \mathrm{L})$ than in the control group $(3.53+0.94 \mu \mathrm{g} / \mathrm{L})$. The urinary mercury level in children who had more than two amalgams or had duration 2 years or more was higher than children who had less than 2 amalgams or had duration less than 2 years. There was no difference in IQ between children with and without amalgam fillings. The children who had amalgam restoration were estimated to be more withdrawn, more anxious/depressed, and to have more social problems than the control group. Furthermore, greater attention problems and delinquent/rule-breaking problems were recorded in the children with amalgam filling than in the control children. Also there was significant increase of serum MDA level and significant decrease of serum levels of GSH, Zn, and GABA levels in amalgam group than the control. These changes were more evident in children who had more than 2 amalgams or had duration 2 years or more.
\end{abstract}

Keywords Mercury; Intelligence; Neurobehavioral Performance, Malondialdehyde; Reduced glutathione; Zinc, Gamma amino butyric acid

\section{Introduction}

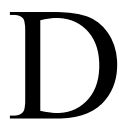
ental amalgam is the most widely used dental restorative material since the early nineteenth century to repair cavities in teeth throughout the world (Timothy et al., 2002; Bates, 2011). Amalgam fillings currently comprise about $50 \%$ mercury, with the remainder principally silver, plus small amounts of copper, tin, or zinc (Fredin, 1994). In many countries amalgam is still the most commonly used filling material especially in posterior teeth (Clarkson, 2002). 
Dental caries may affect more than $90 \%$ of children (Al Dosari et al., 2004; Al-Malik \& Rehbini, 2006) which offers a good argument for amalgam persistent use. However, their use has been controversial particularly in children, as they continually release small amounts of mercury (Bates, 2011). Amalgam is still a valuable material in pediatric dentistry because of its superior physical properties, ease of manipulation, and low cost ( Levy et al., 2004).

Amalgam was thought to be relatively inert once it hardened. However, the elemental mercury it contains readily vaporizes under pressure. It is postulated that stress on the amalgam surface, such as that produced by chewing, grinding of teeth, or tooth brushing, causes the breakdown of a surface barrier and the release of mercury vapor into the mouth. ( Al-Saleh and Al-Sedairi, 2011). When mercury vapors are inhaled, $80 \%$ is readily absorbed in the blood through the lungs and distributed in various organs, mainly in the kidneys where it may become incorporated before being excreted (Gerhardsson and Lundh, 2010). Other organs (brain, lungs, liver, gastrointestinal tract, endocrine glands) show varying degrees of elevated concentrations of mercury although, the brain is the site of greatest sensitivity. Metallic mercury, being lipophilic, can readily cross the bloodbrain and placental barriers where it is oxidized to inorganic mercury. In this state, mercury is not lipophilic and has a limited ability to cross these biological membranes. Thus, mercury can be retained in the brain and fetal tissues ( Levy et al., 2004; Barregard et al., 2010). Although, the amount of mercury from amalgam passing through the gastrointestinal tract may be large, it is poorly absorbed (Levy et al., 2004).

Mercury can cause biochemical damage to tissues and genes through diverse mechanisms, such as interrupting intracellular calcium homeostasis, disrupting membrane potential, altering protein synthesis, interrupting excitatory amino acid pathways in the central nervous system, mitochondrial damage, lipid peroxidation, microtubule destruction and alteration of antioxidant defense mechanisms (Brownawell et al., 2005).

Human cerebral cortical activity may be under the influence of a large number of neuroactive substances which are important for the normal integrity and function of the central nervous system (CNS) which controls a variety of physiological, behavioral, and endocrinal function (Greengard, 2001). Gamma-aminobuttyric acid (GABA) is an important amino acid-based signaling molecule in basic neuronal pathways and acts as the major inhibitory neurotransmitter in CNS. (Kleppner and Tobin, 2001).

A recent Food and Drug Administration (FDA) staff draft white paper stated that no scientific studies have demonstrated harm from dental amalgam. This conclusion, however, was questioned by a scientific advisory panel, which recommended a more extensive review, including data from other countries (Food and Drug Administration, 2006). Based on the ongoing controversy over the safety of dental amalgam, this study was carried out to investigate the effect of dental amalgam restorations on urinary mercury level, intelligence, neurobehavioral function and some biochemical markers among children who had dental amalgam fillings.

\section{Patients and methods}

\section{Study design}

Patients were selected from outpatient clinic of pedodetontic department, faculty of dentistry, Tanta University. Seventy nine children aged 6-14 years old were selected, 59 of them had 1 or more amalgam restoration in their mouths and 20 were control. Informed consent was obtained from the accompanying parents or guardian explaining the nature and purpose of the study.

\section{Exclusion criteria}

Children who had systemic disorders, mental retardation, and those who previously_had psychiatric disorders before amalgam filling were excluded from the study. Children who had amalgam filling placement or replacement for a minimum of 1 month (as the release of mercury from amalgam restoration is at its peak just subsequent to placement in the cavity, declining to steady level by 10 to 15 days (Derand and Johansson, 1983) were also excluded from the study.

The selected children of the present study were divided into two main groups; amalgam group and control group. Amalgam group was divided into:

- Group I: included children who had two amalgam fillings or less and was divided into two subgroups;

- Group I a: include the children who had two amalgam fillings or less since less than two years and

○ Group I b: include the children who had two amalgam fillings or less since two years or more

- Group II: included children who had more than two amalgam fillings and was divided into two subgroups;

- Group II a: include the children who had more than two amalgam fillings since less than two years and

○ Group II b: include the children who had more than two amalgam fillings since two years or more 
All groups were subjected to:

1- Clinical examination: to detect the oral and systemic condition of the child including number of amalgam filling and duration of first amalgam filling.

2- Questionnaire collection: it included age, sex, frequency of fish eating (as fish eating is the main source of organic mercury) and hot food consumption habit: answered "usually" to the question "How often do you eat foods, soups, and drinks when they are still hot.

3- The Child Behavior Checklist (CBCL) (Achenbach et al., 1991) was used to evaluate psychosocial competence and behavioral problems in the recruited children. An Arabictranslated and validated version of the CBCL (El - Defrawi, 1997) was completed by a parent and scored using a computerized scoring software system (Assessment Data Managerversion 9.1). CBCL yields four global T-scores: Competence, Internalizing Behavior Problems, Externalizing Behavior Problems, and Total Problem Behaviors. Three subscales contribute to the Competence score: Activities, Social Adaptation, and School. Eight subscales contribute to the Behavior scores: Withdrawn, Somatic Complaints, Anxious/Depressed, Social Problems, Thought Problems, Attention Problems, Delinquent Behaviors, and Aggression.

4- Intelligence test (IQ): The Arabic Version of the Revised Wechsler Intelligence Scale for Children (WISCR) (Wechsler, 1977; Kamel et al., 1997). This is the most widely used test for intellectual assessment and covers an age range of 6-16 years. The test is scored according to a manual from which verbal and performance scores and intelligent quotient are obtained.

5- Estimation of urinary mercury level: Urine sample was collected from the children in the mornining. Urine samples were immediately frozen and sent for analysis. Inorganic urine mercury was determined by inductively coupled plasma mass spectrometry (ICP-MS)( Qin et al., 2009).

6- Spectrophotometric determination of serum malonaldehyde (MDA) level: This method depends on the formation of MDA as an end product of lipid peroxidation which reacts with thiobarbituric acid producing thiobarbituric acid reactive substance (TBARS), a pink chromogen, which can be measured at $532 \mathrm{~nm}$ (Ohkawa et al., 1979).

7- Spectrophotometric determination of reduced glutathione (GSH) level: The method is based on the reduction of 5,5 dithiobis (2-nitrobenzoic acid) (DTNB) with reduced glutathione (GSH) to produce a yellow compound. The reduced chromogen is directly proportional to GSH concentration and its absorbance can be measured at 405 $\mathrm{nm}$ by using a commercial kit (Biodiagnostic, Egypt) (Sedlak and Lindsay, 1968).

8- Estimation of serum levels of zinc (Zn): Zn level was measured by an atomic absorption spectrophotometery (mode 12380; Perkin Elmer). The monochromatic slit was adjusted to 0.7 and the wave length was set to the zinc resonance line at $213.9 \mathrm{~nm}$. (Pekarek et al., 1972).

9- Flurophotometric determination of serum GABA level: Serum gamma amino butyric acid (GABA content was estimated according to the method of Lowe et al. (1958).

\section{Statistical analysis}

Statistical presentation and analysis of the present study was conducted, using the mean, standard deviation, Analysis of variance [ANOVA] tests, Linear Correlation Coefficient and chi-square test by SPSS V. 16. P value was considered insignificant if more than 0.05 , significant if $\leq 0.05$.

\section{Results}

The demographic characteristics of children with and without amalgam fillings were similar as shown in table 1. Children in the amalgam group had on average two amalgam fillings (range $=1-7$ ). The duration of amalgam exposure (time since first amalgam treatment) ranged from 1 to 50 month. Other exposure indices as sex, type of food and fish consumption did not show statistically significant difference between control and amalgam group regarding the urinary mercury level as shown in table 2 and 5.

The mean level of urinary mercury was significantly higher in the amalgam group (8.15+0.99 $\mu \mathrm{g} / \mathrm{L})$ than in the control group $(3.53+0.94 \mu \mathrm{g} / \mathrm{L})$. The urinary mercury level in children who had more than two amalgams $(8.3 \pm 1.1 \mu \mathrm{g} / \mathrm{L})$ was significantly higher than children who had less than 2 amalgams $(7.97 \pm 0.83 \mu \mathrm{g} / \mathrm{L})$. Additionally, insignificant higher mercury level was observed in children who had treatment for 2 years or 
more $(8.99 \pm 0.35 \mu \mathrm{g} / \mathrm{L})$ than that in children who had amalgam for less than 2 years $(7.35 \pm 0.60 \mu \mathrm{g} / \mathrm{L})$. Moreover, all amalgam groups by different number or different duration revealed significant difference in comparison with control as shown in table 3.

No significant differences in intelligence was detected between the two main groups; Children with and without amalgam fillings (tables 4 and 5).

Regarding neurobehavioral functioning, Children with amalgam fillings had significantly less total competence scores on the CBCL than the control group (table-6). This difference was mainly due to significantly less competence in general activities and scholastic achievement in children of the amalgam group (table-7). When compared to the control group, the amalgam group also scored significantly higher on the total internalizing and externalizing behavioral problems (table-6). On further analysis of these results, differences between the two groups were significant in some but not all behavioral parameters measured by the checklist (table-8). The children with amalgam were estimated to be more withdrawn, more anxious/depressed, and have more social problems than the control group. Furthermore, greater attention problems and delinquent/rule-breaking problems were recorded in children with amalgam filling than in control children (table-8).
As regards the biochemical changes in the present study, table 9 revealed significant increase of serum MDA level $(4.75+1.71 \mathrm{nmol} / \mathrm{ml})$ in amalgam group than the control $(3.53 \pm 0.96 \mathrm{nmol} / \mathrm{ml})$ group, with significant higher levels in children who had more than 2 amalgams or duration 2 years or more when compared to those who had less than 2 amalgams or has duration less than 2 years.

There was significant decrease of serum levels of GSH $(1.76+0.27 \mathrm{mg} / \mathrm{dl}), \mathrm{Zn}(84.99+12.94 \mu \mathrm{g} / \mathrm{dL})$, and GABA $(49.64+16.38 \mu \mathrm{g} / \mathrm{L})$ levels in amalgam group than the control $(2.50 \pm 0.11 \mathrm{mg} / \mathrm{dl}, 109.9 \pm 6.95 \mu \mathrm{g} / \mathrm{dL}$ and $108.11+13.16 \mu \mathrm{g} / \mathrm{L}$ respectively). Additionally, more changes were observed in the children who had more than 2 amalgams or had duration more than 2 years when compared to children who had 2 amalgams or less or has duration less than 2 years concerning GSH and GABA but, not in zinc. Although, GSH, Zn and GABA levels in all amalgam groups revealed significant decrease compared to control (table 10-12). The present study showed significant positive correlation between urinary mercury level and serum MDA level in amalgam group. However, significant negative correlation was found between urinary mercury level and serum GSH and GABA levels and not zinc (table -13).

Table 1: Statistical analysis of demographic data of control and amalgam groups.

\begin{tabular}{|c|c|c|}
\hline & Control group $(n=20)$ & Amalgam group $(n=59)$ \\
\hline Age (year) Mean \pm SD & $10+1.85$ & $9.80+2.27$ \\
\hline \multicolumn{3}{|l|}{ Gender (\%) } \\
\hline Male & 40 & 49.15 \\
\hline Female & 60 & 50.85 \\
\hline \multicolumn{3}{|l|}{ Hot food consumption habit (\%) } \\
\hline Yes & 60 & 84.75 \\
\hline No & 40 & 15.25 \\
\hline \multicolumn{3}{|l|}{ Fish consumption (\%) } \\
\hline No & 40 & 5 \\
\hline $1 \backslash$ month & 20 & 35.59 \\
\hline $1 \backslash 2$ week & 20 & 28.81 \\
\hline $1 \backslash$ week & 20 & 25.42 \\
\hline $2 \backslash$ week & - & 5.08 \\
\hline Median (range) of amalgam fillings & & $2(1-7)$ \\
\hline
\end{tabular}

Table 2: Statistical analysis of mercury level $(\mu \mathrm{g} / \mathrm{L})$ and demographic data in different tested groups.

\begin{tabular}{|l|c|c|}
\hline \multirow{2}{*}{ Sex } & \multicolumn{2}{c|}{ Mercury level } \\
\cline { 2 - 3 } & Control (Mean+SD) & Amalgam (Mean+SD) \\
\hline Male & $3.98+1.2$ & $8.31+0.75$ \\
\hline female & $3.23+1.14$ & $8.01+1.18$ \\
\hline $\mathrm{T}$ & 0.365 & 0.753 \\
\hline $\mathrm{P}$ & 0.477 & 0.615 \\
\hline \multicolumn{2}{|l}{ Hot food consumption habit (\%) } \\
\hline
\end{tabular}




\begin{tabular}{|l|c|c|}
\hline yes & $3.22 \pm 1.13$ & $8.12 \pm 1.02$ \\
\hline no & $3.99 \pm 0.05$ & $8.36+0.89$ \\
\hline $\mathrm{T}$ & 1.632 & 0.626 \\
\hline $\mathrm{P}$ & 0.099 & 0.502 \\
\hline Fish consumption & \multicolumn{2}{|l|}{} \\
\hline no & $3.99 \pm 0.01$ & $8.14 \pm 2.72$ \\
\hline $1 \backslash$ month & $3.99 \pm 0.99$ & $7.79 \pm 0.78$ \\
\hline $1 \backslash 2$ week & $3.98 \pm 0.36$ & $8.41+0.91$ \\
\hline $1 \backslash$ week & $3.71 \pm 0.04$ & $8.15 \pm 0.80$ \\
\hline $2 \backslash$ week & - & $9.27 \pm 0.51$ \\
\hline $\mathrm{F}$ & 1.491 & 1.253 \\
\hline $\mathrm{P}$ & 0.582 & 0.663 \\
\hline
\end{tabular}

*Significant at $P \leq 0.05$ and $P>0.05$ is non-significant.

Table 3: Statistical analysis of urinary mercury levels $(\mu \mathrm{g} / \mathrm{L})$ among control group and different amalgam groups.

\begin{tabular}{|c|c|c|c|c|}
\hline Group & $N$ & Mean \pm SD & T test & P value \\
\hline Control & 20 & $3.53 \pm 0.94$ & 16.185 & \multirow[t]{2}{*}{$0.001^{*}$} \\
\hline Amalgam (total) & 59 & $8.15 \pm 0.99$ & & \\
\hline \multicolumn{5}{|c|}{ By total number of amalgams at the time of participation $(N)$} \\
\hline Group I & 26 & $7.97 \pm 0.83$ & \multirow[t]{2}{*}{9.65} & \multirow[t]{2}{*}{$0.003^{*}$} \\
\hline Group II & 33 & $8.3 \pm 1.1$ & & \\
\hline \multicolumn{5}{|c|}{ By time since first amalgam filling at the time of participation } \\
\hline Group Ia and IIa & 30 & $7.35 \pm 0.60$ & \multirow[t]{2}{*}{0.117} & \multirow[t]{2}{*}{0.733} \\
\hline Group $I b$ and IIb & 29 & $8.99 \pm 0.35$ & & \\
\hline \multicolumn{5}{|c|}{ By number and time of amalgam filling with control } \\
\hline Group Ia & 12 & $7.31+0.79$ & \multirow{4}{*}{$\begin{array}{l}\text { All are significant } \\
F=205.44 \\
P=0.000^{*}\end{array}$} & \\
\hline Group Ib & 14 & $8.55+0.18$ & & \\
\hline Group IIa & 18 & $7.37+0.45$ & & \\
\hline Group IIb & 15 & $9.07+0.85$ & & \\
\hline
\end{tabular}

*Significant at $P \leq 0.05$ and $P>0.05$ is non-significant.

Table 4: Statistical analysis of intelligence of children with and without fillings.

\begin{tabular}{|l|c|c|}
\hline Parameter & control & Amalgam \\
\hline NO. & 15 & 23 \\
\hline IQ $($ Mean \pm SD) & $108.07 \pm 16.24$ & $102.05 \pm 16.84$ \\
\hline T & \multicolumn{2}{|c|}{0.115} \\
\hline P value & \multicolumn{2}{|c|}{0.736} \\
\hline
\end{tabular}

*Significant at $P \leq 0.05$ and $P>0.05$ is non-significant

Table 5: Statistical analysis of correlation between mercury level and other variables in tested groups.

\begin{tabular}{|l|l|l|}
\hline \multirow{2}{*}{} & \multicolumn{2}{|c|}{ Urinary mercury } \\
\cline { 2 - 3 } & $\mathbf{R}$ & $\mathbf{P}$ \\
\hline Fish eating & 0.253 & 0.528 \\
\hline Age & 0.241 & 0.352 \\
\hline Sex & 0.159 & 0.425 \\
\hline Food & 0.259 & 0.741 \\
\hline IQ & 0.529 & 0.698 \\
\hline
\end{tabular}

*Significant at $P \leq 0.05$ and $P>0.05$ is non-significant

Table 6: Statistical analysis of the four global t-scores of the Child Behavior Checklist (CBCL) as compared in the amalgam group versus control group.

\begin{tabular}{|c|c|c|c|c|}
\hline \multirow{2}{*}{ Score } & Control Group $(n=20)$ & Amalgam Group (n=26) & \multirow{2}{*}{ T test } & \multirow{2}{*}{ P value } \\
\hline & Mean \pm SD & Mean \pm SD & & \\
\hline Total competence score & $42.8 \pm 10.27$ & $32 \pm 6.57$ & 3.9 & $0.001 *$ \\
\hline Internalizing behavior problems & $58.9 \pm 10.1$ & $67.9 \pm 7.91$ & 3.4 & $0.002 *$ \\
\hline Externalizing behavior problems & $55.5 \pm 9.05$ & $63.7 \pm 9.58$ & 2.9 & $0.005 *$ \\
\hline
\end{tabular}




\begin{tabular}{|l|c|c|c|}
\hline Total problem behaviors & $58.0 \pm 9.17$ & $66.3 \pm 7.96$ & 3.3 \\
\hline
\end{tabular}

*Significant at $P \leq 0.05$ and $P>0.05$ is non-significant.

Table 7: Statistical analysis of the three competence t-scores of the Child Behavior Checklist (CBCL) as compared in the amalgam group versus control group.

\begin{tabular}{|c|c|c|c|c|}
\hline Score & $\begin{array}{c}\text { Control Group }(\mathrm{n}=20) \\
\text { Mean } \pm \text { SD }\end{array}$ & $\begin{array}{c}\text { Amalgam Group }(\mathrm{n}=26) \\
\text { Mean } \pm \text { SD }\end{array}$ & T test & P value \\
\hline Activities score & $42.4 \pm 7.8$ & $31.1 \pm 7.7$ & 4.7 & $0.001^{*}$ \\
\hline Social adaptation score & $42.6 \pm 8.8$ & $40.9 \pm 8.8$ & 0.62 & 0.5 \\
\hline Scholastic achievement & $52 \pm 7$ & $44.4 \pm 7.4$ & 3.5 & $0.001^{*}$ \\
\hline
\end{tabular}

*Significant at $P \leq 0.05$ and $P>0.05$ is non-significant.

Table 8: Statistical analysis of the t-scores of eight behavioral subscales in the Child Behavior Checklist (CBCL) as compared in the amalgam group versus control group.

\begin{tabular}{|l|c|c|c|c|}
\hline \multicolumn{1}{|c|}{ Score } & $\begin{array}{c}\text { Control Group (n=20) } \\
\text { Mean } \pm \text { SD }\end{array}$ & $\begin{array}{c}\text { Amalgam Group (n=26) } \\
\text { Mean } \pm \text { SD }\end{array}$ & T test & P value \\
\hline Withdrawn & $59.5 \pm 9.5$ & $65.7 \pm 10.5$ & 2.1 & $0.04^{*}$ \\
\hline Somatic complaints & $57.8 \pm 7.6$ & $60.7 \pm 7.1$ & 1.3 & 0.19 \\
\hline Anxious/depressed & $59.1 \pm 7.4$ & $68.5 \pm 9.7$ & 3.6 & $0.001^{*}$ \\
\hline Social problems & $57.3 \pm 7.2$ & $64.4 \pm 7.5$ & 3.2 & $0.002^{*}$ \\
\hline Thought problems & $60.2 \pm 6.7$ & $58.4 \pm 8.1$ & 0.81 & 0.4 \\
\hline Attention problems & $55.4 \pm 4.5$ & $60.5 \pm 7.7$ & 2.8 & $.007^{*}$ \\
\hline Delinquent behaviors & $52.4 \pm 3.4$ & $63 \pm 8.1$ & 6.01 & $0.001^{*}$ \\
\hline Aggression & $59.1 \pm 9.3$ & $64.6 \pm 11.5$ & 0.08 \\
\hline
\end{tabular}

*Significant at $P \leq 0.05$ and $P>0.05$ is non-significant.

Table 9: Statistical analysis of serum MDA level ( $\mathrm{nmol} / \mathrm{ml})$ among control group and different amalgam group.

\begin{tabular}{|c|c|c|c|c|}
\hline Group & $N$ & Mean \pm SD & T test & P value \\
\hline Control & 10 & $3.53 \pm 0.96$ & \multirow[t]{2}{*}{2.165} & \multirow[t]{2}{*}{$0.03 *$} \\
\hline Amalgam (total) & 40 & $4.75+1.71$ & & \\
\hline \multicolumn{5}{|c|}{ By total number of amalgams at the time of participation $(N)$} \\
\hline Group I & 20 & $3.86 \pm 1.02$ & \multirow[t]{2}{*}{45.449} & \multirow[t]{2}{*}{$0.000 *$} \\
\hline Group II & 20 & $5.65 \pm 1.81$ & & \\
\hline \multicolumn{5}{|c|}{ By time since first amalgam filling at the time of participation } \\
\hline Group Ia and IIa & 20 & $4.41 \pm 0.5$ & \multirow[t]{2}{*}{149.33} & \multirow[t]{2}{*}{$0.000 *$} \\
\hline Group Ib and IIb & 20 & $5.1 \pm 2.3$ & & \\
\hline \multicolumn{5}{|c|}{ By number and time of amalgam filling with control } \\
\hline Group Ia & 10 & $4.82 \pm 0.96$ & \multirow{4}{*}{\multicolumn{2}{|c|}{$\begin{array}{l}\text { All are significant except control, group Ib, \& IIa } \\
\boldsymbol{F}=74.95 \\
\boldsymbol{P}=0.000 *\end{array}$}} \\
\hline Group Ib & 10 & $2.90 \pm 0.31$ & & \\
\hline Group IIa & 10 & $3.99 \pm 0.29$ & & \\
\hline Group IIb & 10 & $7.29 \pm 0.87$ & & \\
\hline
\end{tabular}

*Significant at $P \leq 0.05$ and $P>0.05$ is non-significant.

Table 10: Statistical analysis of serum GSH (mg/dl) levels among control group and different amalgam group.

\begin{tabular}{|l|c|c|c|c|}
\hline \multicolumn{1}{|c|}{ Group } & $\boldsymbol{N}$ & Mean \pm SD & T test & P value \\
\cline { 1 - 3 } Control & 10 & $2.50 \pm 0.11$ & \multirow{2}{*}{$0.04 \%$} \\
\hline Amalgam (total) & 40 & $1.76 \pm 0.27$ & & \\
\hline
\end{tabular}




\begin{tabular}{|c|c|c|c|c|}
\hline \multicolumn{5}{|c|}{ By total number of amalgams at the time of participation $(\mathrm{N})$} \\
\hline Group I & 20 & $1.56 \pm 0.21$ & \multirow[t]{2}{*}{11.34} & \multirow[t]{2}{*}{$0.002 *$} \\
\hline Group II & 20 & $1.97 \pm 0.14$ & & \\
\hline \multicolumn{5}{|c|}{ By time since first amalgam filling at the time of participation } \\
\hline Group Ia and IIa & 20 & $1.62 \pm 0.27$ & \multirow[t]{2}{*}{12.38} & \multirow[t]{2}{*}{$0.001 \%$} \\
\hline Group Ib and IIb & 20 & $1.91 \pm 0.19$ & & \\
\hline \multicolumn{5}{|c|}{ By number and time of amalgam filling with control } \\
\hline Group Ia & 10 & $2.06 \pm 0.14$ & \multirow{4}{*}{\multicolumn{2}{|c|}{$\begin{array}{l}\text { All are significant } \\
\boldsymbol{F}=158.09 \\
\boldsymbol{P}=0.000 *\end{array}$}} \\
\hline Group Ib & 10 & $1.88 \pm 0.03$ & & \\
\hline Group IIa & 10 & $1.75 \pm 0.09$ & & \\
\hline Group IIb & 10 & $1.37 \pm 0.06$ & & \\
\hline
\end{tabular}

*Significant at $P \leq 0.05$ and $\mathrm{P}>0.05$ is non significant.

Table 11: Statistical analysis of serum Zinc ( $\mu \mathrm{g} / \mathrm{dL})$ level among control group and different amalgam group.

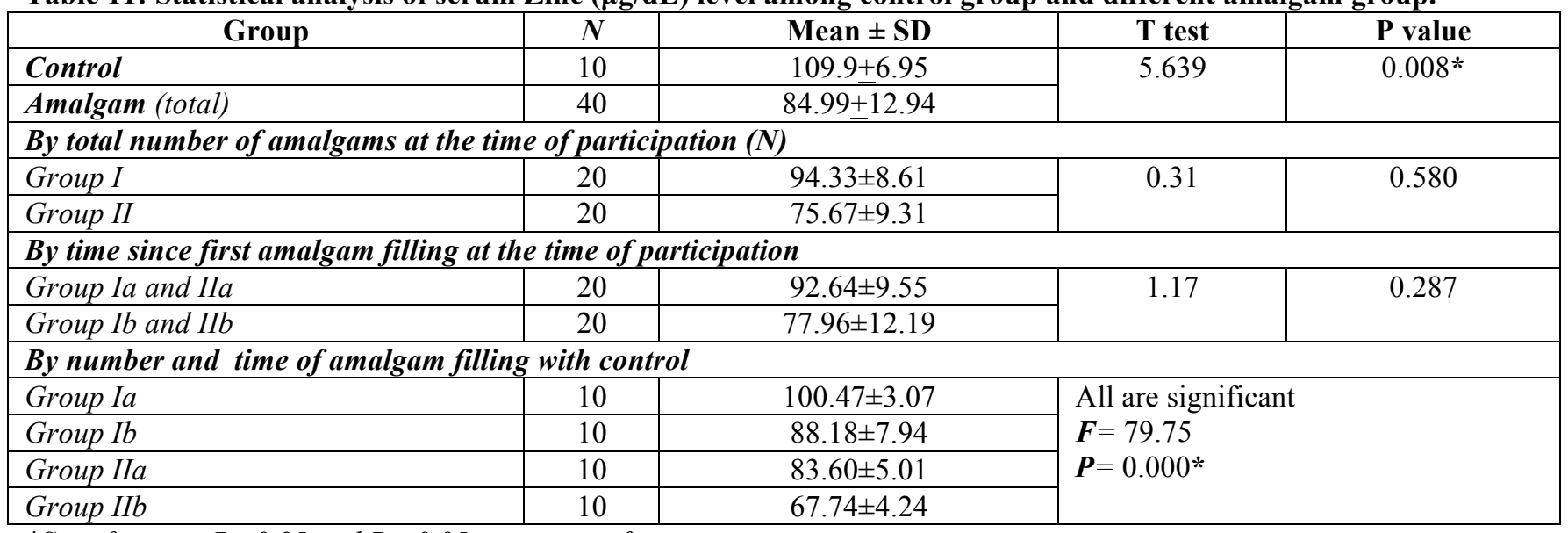

*Significant at $P \leq 0.05$ and $P>0.05$ is non-significant.

Table 12: Statistical analysis of serum GABA $(\mu \mathrm{g} / \mathrm{L})$ level among control group and different amalgam group

\begin{tabular}{|c|c|c|c|c|}
\hline Group & $N$ & Mean \pm SD & T test & P value \\
\hline Control & 10 & $108.11+13.16$ & \multirow[t]{2}{*}{15.325} & \multirow[t]{2}{*}{$0.001 *$} \\
\hline Amalgam (total) & 40 & $49.64+16.38$ & & \\
\hline \multicolumn{5}{|c|}{ By total number of amalgams at the time of participation $(N)$} \\
\hline Group I & 20 & $59.01 \pm 17.49$ & \multirow[t]{2}{*}{109} & \multirow[t]{2}{*}{$0.000 *$} \\
\hline Group II & 20 & $40.27 \pm 7.79$ & & \\
\hline \multicolumn{5}{|c|}{ By time since first amalgam filling at the time of participation } \\
\hline Group Ia and IIa & 20 & $61.61 \pm 14.84$ & \multirow[t]{2}{*}{110.14} & \multirow[t]{2}{*}{$0.000 \%$} \\
\hline Group Ib and IIb & 20 & $37.68 \pm 5.44$ & & \\
\hline \multicolumn{5}{|c|}{ By number and time of amalgam filling with control } \\
\hline Group Ia & 10 & $75.77 \pm 3.71$ & \multirow{4}{*}{\multicolumn{2}{|c|}{$\begin{array}{l}\text { All are significant } \\
\boldsymbol{F}=224.59 \\
\boldsymbol{P}=0.000^{*}\end{array}$}} \\
\hline Group Ib & 10 & $42.26 \pm 2.87$ & & \\
\hline Group IIa & 10 & $47.45 \pm 2.45$ & & \\
\hline Group IIb & 10 & $33.09 \pm 2.73$ & & \\
\hline
\end{tabular}

*Significant at $P \leq 0.05$ and $P>0.05$ is non-significant.

Table 13: Statistical analysis of correlation between mercury level and biochemical variables (in MDA, GSH, zinc, \& GABA) in tested groups.

\begin{tabular}{|l|c|c|}
\hline \multirow{2}{*}{} & \multicolumn{2}{|c|}{ Urinary mercury } \\
\cline { 2 - 3 } & $\mathbf{R}$ & $\mathbf{P}$ \\
\hline Serum MDA & 0.642 & $0.001^{*}$ \\
\hline Serum GSH & -0.556 & $0.001^{*}$ \\
\hline Serum zinc & 0.247 & 0.084 \\
\hline
\end{tabular}




\author{
\begin{tabular}{|l|l|l|}
\hline Serum GABA & -0.559 & $0.001 *$ \\
\hline
\end{tabular} \\ *Significant at $P \leq 0.05$ and $P>0.05$ is non-significant.
}

\section{Discussion}

Mercury $(\mathrm{Hg})$ is a naturally occurring metal that exists in three chemical forms: organic, inorganic and elemental. Each form has its own profile of toxicity and source of exposure. While, diet, especially fish and other seafoods are the main sources of exposure to organic $\mathrm{Hg}$, dental amalgam is an important source of elemental $\mathrm{Hg}$ vapor (Clarkson and Magos, 2006).

The present study has clearly demonstrated the association between dental amalgam fillings and the levels of $\mathrm{Hg}$ in children urine samples. The urinary mercury level (UHg) showed significant increase in the amalgam group $(8.15+0.99)$ compared to control $(3.53+0.94)$. Previous studies comparable to the present study showed widely varying results of mean mercury level in children with and without amalgam respectively 0.4 and 0.2 Wilhelm et al. (2006) 1.5 and 1.4 Woods et al. (2007) 0.92 and 0. 21 Link et al. (2007) 0.1 and $<0.1$ Schulz et al. (2009) 3.749 and $2.853 \mu \mathrm{g} / \mathrm{L}$ Al-Saleh and Al-Sedairi (2011). Although, Ye et al. (2009) found that urinary mercury concentrations for children with and without amalgam filling were not different.

Urine samples provide the best marker of body burden of mercury from low-level long-term exposure to elemental and inorganic mercury. As mercury release from amalgam is absorbed and then oxidized to inorganic divalent mercury $\left(\mathrm{Hg}^{2+}\right)$ in vivo then excreted via the urine (International Program on Chemical Safety, 2003).

The level of urinary mercury of control children in the present study was higher than many studies in other countries. However, the level of the present study is in the range of general background levels of unexposed children who should have urinary $\mathrm{Hg}$ levels $<5 \mu \mathrm{g} / \mathrm{L}$ (Ozuah et al., 2003; Bose-O'Reilly et al., 2010). Comparing results of this study to the defined reference value for UHg by the German Commission of Human Biomonitoring for $\mathrm{UHg}$ in children (3-14 year olds), $100 \%$ of children's urinary $\mathrm{Hg}$ concentrations without fillings were above the reference value of $0.4 \mu \mathrm{g} / \mathrm{L}$ (Schulz et al., 2009). Additionally, Schulz et al. (2009) reported that $\mathrm{UHg}$ for children with more than two dental amalgams was $3.1 \mu \mathrm{g} / \mathrm{L}$. In this study, children with dental amalgam had a considerably higher level of mercury $(8.15+0.99 \mu \mathrm{g} / \mathrm{L})$. this is in accordance with a study done in Saudi Arabia which reported that children with dental amalgam had a considerably high mercury level of $8.538 \mu \mathrm{g} / \mathrm{L}$, with a range of 3.129 to 15.575 $\mu \mathrm{g} / \mathrm{L}$ ( Al-Saleh and Al-Sedairi, 2011). This may be attributed to that mercury hygiene is not strictly adhered.

The present study revealed absence of correlation between fish consumption and urinary mercury level; this is in agreement of Ye et al. (2009) who stated that there is no effect of fish consumption on the urinary mercury level. Furthermore, Leistevuo et al. (2001) found a three-fold increase of mercury levels in saliva of individuals with dental amalgam compared to individuals without amalgam, although frequency and kind of fish consumption were identical in both groups. These findings are contradicted by another study which found that fish intake significantly influenced the $\mathrm{UHg}$ levels as children who reported higher levels of fish consumption excrete significantly elevated amounts of $\mathrm{Hg}$ (Apostoli et al., 2002; Levy et al., 2004). The outcome of the present study on fish is not somewhat surprising since $\mathrm{Hg}$ in fish is mainly methyl- $\mathrm{Hg}$, which is not excreted through the kidney (Clarkson et al., 1988; WHO, 1996). The null results on fish consumption may be due to the difference in fish species consumed across populations. Mercury levels in fish vary also in different areas (International Program on Chemical Safety, 1990). Additionally, food consumption in the children of the present study was very low compared to the frequency of fish eating in other countries.

The present study revealed significant increase in urinary mercury level in children with more than two amalgams than those with 2 amalgams or less. Previous studies in children have shown that urinary mercury concentrations were correlated with the number of amalgam fillings (Woods et al., 2007; Dunn et al., 2008). This association was not found in the studies of KhordiMood et al. (2001) and Ye et al. (2009).

The present research did not find positive relation of urinary mercury levels and time since first amalgam filling, this finding is inconsistent with that of the two recent clinical trials (Woods et al., 2007; Ye et al., 2009). The mechanism of this association is unclear and may be related to cumulative deposition of inorganic mercury in the kidney and its excretion in urine. However, as a matter of fact, after two years of mercury exposure the route of kidney excretion of mercury appears to be less effective as increased mercury exposure inhibits its own excretion. Additionally, over $90 \%$ of mercury leaves the body through the biliary transport system of the liver and excreted in the feces, not in the urine (Lorscheider et al., 1995). Mutter et al. (2004) reported that possible adverse effects of mercury may need more than five years of mercury exposure to develop. If mercury is involved in the pathogenesis of Alzheimer's disease, the disease may need up to 50 years to be clinically diagnosed.

Absence of correlation between amalgam filling and intelligence in the present study were consistent with two clinical trials. The first study was conducted in Lisbon, Portugal, 507 children were randomly assigned to receive either amalgam $(n=254)$ or composite $(n=253)$ and were followed for 7 years (1997-2005). No statistically significant differences in neurobehavioral assessment (memory, attention, motor development, nerve conduction velocities) or intelligence were found 
between the two groups (DeRouen et al., 2006). The second study was conducted in two US cities followed 534 children (267 for amalgam and 267 for resin composite) for 5 years. Likewise, there were no statistically significant differences in full-scale IQ scores, memory, or visuomotor ability between children with and without amalgam (Bellinger et al., 2006, 2007 and 2008). The result of the present study on IQ could be explained by the fact that heritability is a major factor in general cognitive ability (Plomin et al., 1994).

The neurobehavioral outcome predictors of the current study were totally different from those of the main trials done in other countries. While our results indicate clear differences between the amalgam group and the control group regarding several competence and behavioral parameters, other trials (Bellinger et al., 2008; Ye et al., 2009) showed no significant differences between the two groups regarding those parameters or any other behavioral parameters. The second study even showed better competence and behavioral performance in children with amalgam when compared to the control group. This disparity of the results comes in spite of using the same psychometric tool, namely the Child Behavior Checklist, validated for different cultures (the Chinese culture in the first study and the Arabic culture in ours).

These differences between our study and previous studies come in accordance with the disparity in the urinary mercury levels reported to be much higher in our study than in the cited studies. The differences between the amalgam types or manipulations used in Egypt versus those used in other countries, might explain some of the adverse competence and behavioral outcomes reported in our children. Other possible explanations may include the decreased levels of the inhibitory neurotransmitter, GABA, in our study. This decreased level might lead to dysfunctioning of the inhibitory control circuits in the brains of children with amalgam fillings leading to less attention, more delinquent behavior and hence lower scholastic achievement despite their average intelligence. Alteration of GABA plasma levels was previously associated with neurobehavioral and mood disorders in children (Prosser and Hughes, 1997).

As regards the biochemical changes in the present study, there was significant increase of serum MDA level accompanied by significant decrease in the serum GSH, zinc and GABA levels in amalgam group as compared to the control group, more changes were documented in the children who had more than two amalgams and those who had treatment for 2 years or more than other groups.

Malondialdeyde (MDA) is one of the termination end products of lipid peroxidation generated during the oxidative breakdown of lipids, and it is a marker of oxidative stress (Eraslan et al., 2004). Both in vivo and in vitro models showed that $\mathrm{Hg}$ exposure can cause oxidative stress in biological systems with generation of reactive oxygen species (ROS), glutathione
(GSH) depletion, and decrease of sulphydryl groups ($\mathrm{SH}$ ) of proteins, which can lead to pathological processes (Shenker et al., 2002; Crespo-López et al., 2007; Augusti et al., 2008; Grotto et al., 2009).

GSH is the main antioxidant in mammalian cells, constituting nearly $90 \%$ of the intracellular nonprotein thiol. It is important for maintaining the intracellular redox status of protein thiols, for protection against endogenous and exogenous sources of oxidative stress, and for the conjugation and excretion of toxic molecules (Rico et al., 2006). In the present study, we observed decreased level of GSH. Only Pizzichini et al. (2002 and 2003) has demonstrated a negative correlation between total antioxidant power and salivary and plasma $\mathrm{Hg}$ in amalgam treated patients . Similarly, (Grotto et al., 2010) observed negative correlation between mercury exposure and GSH level in Amazonian communities. He attributed this to the interaction of $\mathrm{Hg}$ with sulphydryl groups of $\mathrm{GSH}$, resulting in diminished GSH concentration which, is considered as the most important mechanism for $\mathrm{Hg}$-induced oxidative damage.

The increased serum MDA and concomitant decrease of GSH levels in amalgam group in our study can be considered as an indicator for the effect of mercury in aggravation of oxidative stress. it has been revealed that exposure to mercury (organic or inorganic) can enhance the induction of oxidative stress and generation of free radicals as result of the depletion of the GSH (Flora et al., 2008). A growing amount of data provides evidence that mercury capable of interacting with nuclear proteins and DNA and increasing the production of reactive radicals such as superoxide, hydrogen peroxide and hydroxyl radicals which cause oxidative deterioration of biological macromolecules, resulting in cellular damage like depletion of enzyme activities, damage to lipid bilayer membrane as well as DNA fragmentation, which can result in the disruption of nerve cell function and integrity (Nur Özdabaka et al., 2008).

Zinc $(\mathrm{Zn})$ is an essential trace element for all forms of life. It contributes to a number of important biological processes include gene expression, DNA synthesis, enzymatic catalysis, hormonal storage and release, memory process as well as neurotransmitter (Vallee \& Auld, 1993). There are several potential mechanisms for the decreased zinc level in the present study. A possible explanation might be that $\mathrm{Hg}$ causes $\mathrm{Zn}$ displacement and execrtion (Grotto et al., 2010). A second explanation may be damage to stomach and intestinal lining by mercury which along with its ability to bind to $\mathrm{SH}$ in cell membranes can alter permeability and adversely alters bacterial populations in the intestine causing leaky gut syndrome and enzyme blockages with poor nutrient absorption (Bensefa-Colas et al., 2011; Suzuki et al., 2011).

Given that GABA is the main inhibitory neurotransmitter in the mammalian nervous system, prolonged disruptions of its function may underlie the sub-clinical impacts of $\mathrm{Hg}$ on health (Basu et al., 2010). 
The decreased GABA level in the present study may be due to the inhibitory effect of mercury on neurotransmitters production by inhibiting: calciumdependent neurotransmitter release (Gassó et al., 2001) or blocking neurotransmitter amino acids synthesis (Belletti and Gatti, 2002). Furthermore, the neurotransmitter GABA is biosynthesized from glutamate catalyzed by the enzyme glutamic acid decarboxylase (GAD). Mercury inhibited GAD activity at low micromolar concentrations in the cortical tissues. This inhibition was likely due to the interaction of $\mathrm{Hg}$ with essential sulfhydryl groups on the GAD protein (Basu et al., 2010).

Many calls to continue, reduce, or ban mercury use have been issued, while some suggest that patients should be informed of the recognized benefits and risks (Spencer, 2000; Mitchell et al., 2005; Martin and Woods, 2006 ). Few restrictions limit the use of amalgam worldwide. Sweden may become the first country to entirely eliminate the use of amalgam (Gelband, 1998). Germany has recommended the restriction of its use in young children, pregnant women, and patients with severe kidney problems (Harhammer, 2001). Likewise, its use has seen a decreasing trend in the USA, Australia, Scandinavia, and to a lesser extent in the UK (Burke, 2004).

\section{Recommendations}

It is clear from this study that research and public enquiry on this issue should continue to solve the subject of debate. Improvements in the alternative restorative materials should be encouraged. The use of precapsulated alloy should be used to eliminate the sources of mercury vapor from spilling large quantities of mercury and subsequent squeezing of the amalgam mass to express excess mercury before packing the amalgam into cavity. The possible adverse effects associated with mercury toxicity can be minimized with proper mercury hygiene. Mercury rich particles during condensation of amalgam should be strictly dispersed otherwise it can be inhaled by the patients and dental personnel. Contaminated disposable materials should be placed in polyethylene bags and sealed before disposal by environmental agencies.

\section{Acknowledgments}

This study is deeply indebted to Mr. Ahmed ELZawawy, Cinical Psychologist at Tanta Psychiatry and Neurology Center, who kindly performed the I.Q test for children recruited in the study.

\section{References}

Achenbach TM, Howell CT, Quay HC et al., (1991): National survey of problems and competencies among four- to sixteen-year-olds: parents' reports for normative and clinical samples. Monogr Soc Res Child Dev. 56(3): 1-131.
Al Dosari AM, Wayne AH, Akpata ES et al., (2004): Caries prevalence and its relation to water fluoride levels among school children in Central Province of Saudi Arabia. Int Dent J. 54:424428.

Al-Malik MI and Rehbini YA (2006): Prevalence of dental caries severity and pattern in age 6 to 7 year old children in a selected community in Saudi Arabia. J Contemp Dent Pract. 7:46-54.

Al-Saleh I and Al-Sedairi A (2011): Mercury (Hg) burden in children: The impact of denta amalgam. Science of The Total Environment. 409 (16):3003-3015.

Apostoli P, Cortesi I, Mangili A et al., (2002): Assessment of reference values for mercury in urine. Sci. Total Environ. 289: 13-24.

Augusti PR, Conterato GMM, Somacal S et al., (2008): Effect of astaxanthin on kidney function impairment and oxidative stress induced by mercury chloride in rats. Food Chem Toxicol. 46:212-219.

Barregard L, Fabricius-Lagging E, Lundh $\mathrm{T}$ et al., (2010): Cadmium, mercury and lead in kidney cortex of living kidney donors: Impact of different exposure sources. Environ Res. 110 1: 47-52.

Basu N, Scheuhammer M, Rouvinen-Watt K et al., ( 2010): In vitro and whole animal evidence that methylmercury disrupts GABAergic systems in discrete brain regions in captive mink. Comparative Biochemistry and Physiology Part C: Toxicology \& Pharmacology. 151(3): 379385.

Bates MN (2011): Dental Amalgam Fillings: A Source of Mercury Exposure. Encyclopedia of Environmental Health. P. 11-20.

Belletti S and Gatti R (2002): Time course assessment of methylmercury effects on C6 glioma cells: submicromolar concentrations induce oxidative DNA damage and apoptosis. J Neurosci Res. 70(5):703-711.

Bellinger DC, Daniel D, Trachtenberg F et al., (2007): Dental amalgam restorations and children's neuropsychological function: the New England children's amalgam. Trial. Environ. Health Perspect. 115:440-446.

Bellinger DC, Trachtenberg F, Barregard L et al., (2006): Neuropsychological and renal effects of amalgam in children: a randomized clinical trial. J. Am. Med. Assoc. 295: 1775-1783.

Bellinger DC, Trachtenberg F, Zhang A et al., (2008): Dental amalgam and psychosocial status: the New England children's amalgam. Trial. J. Dent. Res. 87: 470-474.

Bensefa-Colas L, Andujar P and Descatha A (2011): Mercury poisoning. Rev Med Interne. 32(7):416-424.

Bose-O'Reilly S, McCarty KM, Steckling N et al., (2010): Mercury exposure and children's health. 
Curr Probl Pediatr Adolesc Health Care. 40: 186-215.

Brownawell AM, Berent S, Brent RL et al., (2005): The potential adverse health effects of dental amalgam. Toxicol.Rev. 24:1-10.

Burke FJ (2004): Amalgam to tooth-colored materialsimplications for clinical practice and dental education: governmental restrictions and amalgam-usage survey results. J Dent. 32: 343350 .

Clarkson TW (2002): The three modern faces of mercury. Environ. Health Perspect. 110 (1): 1123.

Clarkson TW and Magos L (2006): The toxicology of mercury and its chemical compounds. Crit Rev Toxicol. 36: 609-662.

Clarkson TW, Hursch JB, Sager PR et al., (1988): Mercury In: Biological Monitoring of Toxic Metals. Clarkson TW, Friberg L, Nordberg GF et al., (eds.), Plenum, New York, pp. 199-246.

Crespo-López ME, Herculano AM, Burbano RR et al., (2007): Methylmercury genotoxicity: a novel effect in human cells lines of the central damage as possible mechanisms. Arch Toxicol. 83:653662.

Derand $\mathrm{T}$ and Johansson B (1983): Corrosion of amalgam. Scand J Dent Res. 91:55-60.

DeRouen TA, Martin MD and Leroux BG (2006): Neurobehavioral effects of dental amalgam in children: a randomized clinical trial. JAMA. 295(15):1784-1792.

Dunn JE, Trachtenberg FL, Barregard L et al., (2008): Scalp hair and urine mercury content of children in the Northeast United States: the New England children's amalgam trial. Environ. Res. 107: 7988.

El - Defrawi MH (1997): Psychiatric Disorders in a Sample of Egyptian Preschool Children. Egyptian Journal of Psychiatry. 20: 271-282.

Eraslan G, Cam Y and Eren M (2004): Changes in malondialdehyde level and catalase activity and effect of toltrazuril on these parameters in chicks infected with Eimeria tenella. Bull. Vet. Inst. Pulawy. 48: 251-254.

Flora SJ, Mittal M and Mehta A (2008): Heavy metal induced oxidative stress \& its possible reversal by chelation therapy. Indian $\mathrm{J}$ Med Res. 128(4):501-523.

Food and Drug Administration (2006): Joint Meeting of the Dental Products Panel (CDRH) and the Peripheral and Central Nervous System Drugs Advisory Committee (CDER), September 6-7, 2006 (Summary).

Fredin B (1994): Mercury release from dental amalgam fillings. Int. J. Risk Saf. Med. 4: 197-208.

Gassó S, Cristòfol RM, Selema G et al., (2001): Antioxidant compounds and $\mathrm{Ca}(2+)$ pathway blockers differentially protect against methylmercury and mercuric chloride neurotoxicity. J Neurosci Res. 66(1):135-145.

Gelband H (1998): The science and politics of dental amalgam. Int $\mathrm{J}$ Technol Assess Health Care. 14:123-134.

Gerhardsson L and Lundh T (2010): Metal concentrations in blood and hair in pregnant females in southern Sweden. J Environ Health. 72 6: $37-41$.

Greengard P (2001): The neurobiology of slow synaptic transmission. Science. 294:1024-1030.

Grotto D, Barcelos GM, Garcia SC et al., (2009): Low level and sub-chronic exposure to methylmercury induces hypertension in rats: nitric oxide depletion and oxidative damage as possible mechanisms. Arch Toxicol. 83:653662.

Grotto D, Valentini J, Fillion M et al., (2010): Mercury exposure and oxidative stress in communities of the Brazilian Amazon. Jr. Science of the Total Environment. 408: 806-811.

Harhammer R (2001): Risk assessment of the dental filling material amalgam. Bundesgesundheitsblatt Gesundheitsforschung Gesundheitsschutz. 44: 149-154. (Abstract)

International Program on Chemical Safety (1990): Environmental Health Criteria 101: Methlymercury. World Health Organization, Geneva, Switzerland.

International Program on Chemical Safety (2003): Elemental Mercury and Inorganic Mercury Compounds 50: Human Health Aspects, World Health Organization, Geneva, Switzerland.

Kamel M, Ismail E and Wechsler D (1997): Intelligence Scale for Children, Arabic Version. Cairo: ELNahda El- Massryia.

Khordi-Mood M, Sarraf-Shirazi AR and Balali-Mood M (2001): Urinary mercury excretion following amalgam filling in children. J. Toxicol. Clin. Toxicol. 39: 701-705.

Kleppner S and Tobin A (2001): GABA signalling therapeutic targets for epilepsy, parkinson's disease Huntington's disease. Emerging Therapeutic Tagets. 5:219-239.

Leistevuo J, Leistevuo T, Helenius H et al., (2001): Dental amalgam fillings and the amount of organic mercury in human saliva. Caries Res. 35:163-166.

Levy M, Schwartz S, Dijak M et al., (2004): Childhood urine mercury excretion: dental amalgam and fish consumption as exposure factors. Environmental Research. 94 (3): 283-290.

Link B, Gabrio T, Piechotowski I et al., (2007): Environmental Health Survey (BW-EHS) from 1996 to 2003, toxic metals in blood and urine of children. Int J Hyg Environ Health. 210:357371.

Lorscheider FL, Vimy MJ and Summers AO (1995): Mercury exposure from "silver" tooth fillings: 
emerging evidence questions a traditional dental paradigm. FASEB. 9:504-508.

Lowe I.P, Robins E and Eyerman GS (1958): The fluorimetric measurement of glutamic, decarboxylase measurement and its distribution in brain. J Neuro chem. 3: 8- 18.

Martin MD and Woods JS (2006): The safety of dental amalgam in children. Exp Opin Drug Saf. 5: 773-781.

Mitchell RJ, Osborne PB and Haubenreich JE (2005): Dental amalgam restorations: daily mercury dose and biocompatibility. J Long Term Eff Med Implants. 15: 709-721.

Mutter J, Naumann J, Sadaghiani C et al., (2004): Alzheimer Disease: Mercury as a pathogenic factor and apolipoprotein $\mathrm{E}$ as a moderator. Neuro Endocrinol Lett. 25:275-283.

Nur Özdabaka S K, Akgülc N, Polatd F et al., (2008): The effects of amalgam restorations on plasma mercury levels and total antioxidant activity. Archieve of oral biology. 53(12):1101-1106.

Ohkawa H, Ohishi N and Yagi K (1979): Assay for lipid peroxides in animal tissues by thiobarbituric acid reaction. Anal. Biochem. 95: 351-358.

Ozuah PO, Lesser MS, Woods JS et al., (2003): Mercury exposure in an urban pediatric population. Ambul Pediatr. 3:24-26.

Pekarek AS, Beisel WR, Bartelloni PJ et al., (1972): Determination of serum zinc concentrations in normal adult subjects by atomic absorption spectrophotometry. Am. J. Clin. Pathol. 57:506510.

Pizzichini M, Fonzi M, Giannerini F et al., (2003): Influence of amalgam fillings on $\mathrm{Hg}$ levels and total antioxidant activity in plasma of healthy donors. Science of The Total Environment. 301 (1-3): 43-50.

Pizzichini M, Fonzi M, Sugherini L et al., (2002): Release of mercury from dental amalgam and its influence on salivary antioxidant activity. Sci Total Environ. 284: 19-25.

Plomin R, Pedersen NL, Lichtenstein P et al., (1994): Variability and stability in cognitive abilities are largely genetic later in life. Behavior Genetics. 24 (3): 207-215.

Prosser J and Hughes CW (1997): Plasma GABA in children and adolescents with mood, behavior, and comorbid mood and behavior disorders: a preliminary study. J Child Adolesc Psychopharmacol. 7(3): 181-199.

Qin L, Wang X, Li W et al., (2009): The Minerals and Heavy Metal in Cow's Milk from China and Japan. Journal of Health Science. 55(2): 300305.
Rico GM, Puchades MJ, Ramón RG et al., (2006): Effect of hemodialysis therapy on oxidative stress in patients with chronic renal failure. Nefrología. 26:218-225.

Schulz C, Angerer J, Ewers U et al., (2009): Human Biomonitoring Commission of the German Federal Environment Agency. Int J Hyg Environ Health. 212:637-647.

Sedlak J and Lindsay RH (1968): Estimation of total, protein-bound,and nonprotein sulfhydryl groups in tissue with Ellman's reagent. Anal Biochem. 25: 192-205.

Shenker BJ, Pankoski L, Zekavat A et al., (2002): Mercury-induced apoptosis in human lymphocytes: caspase activation is linked to redox status. Antioxid Redox Signal. 4:379-389.

Spencer AJ (2000): Dental amalgam and mercury in dentistry. Aust Dent J. 45: 224-234.

Suzuki Y, Inoue T and Ra C (2011): Autoimmunityinducing metals (hg, au and ag) modulate mast cell signaling, function and survival. Curr Pharm Des. 17(34):3805-3814.

Timothy A D, Brian GL, Michael DM et al., (2002): Issues in design and analysis of a randomized clinical trial to assess the safety of dental amalgam restorations in children. Controlled Clinical Trials. 23(3):301-320.

Vallee BL and Auld DS (1993): Zinc: biological functions and coordination motifs. Accts Chem. Res. 26:543-551.

Wechsler D (1977): Manual for the Wechsler Intelligence Scale for Children- Revised (WISC-R). New York: The Psychological Corporation.

WHO "World Health Organisation" (1996): Inorganic mercury. In: Biological Monitoring of Chemical Exposure in the Workplace, Guidelines, Vol. 1. World Health Organisation, Geneva.

Wilhelm M, Schulz C and Schwenk M (2006): Revised and new reference values for arsenic, cadmium, lead and mercury in blood or urine of children, basis for validation of human biomonitoring data in environmental medicine. Int $\mathrm{J}$ Hyg Environ Health. 209:301-305.

Woods J, Martin M, Leroux B et al., (2007): The contribution of dental amalgam to urinary mercury excretion in children. Environ Health Perspect. 115:1527-1531.

Ye X, Qian H, Xu P et al., (2009): Nephrotoxicity, neurotoxicity, and mercury exposure among children with and without dental amalgam fillings. International Journal of Hygiene and Environmental Health. 212 (4):378-386. 
الملخص العربي

مستوى الزئبق في البول و تقييم السلولك العصبي وبعضي مملفم الدلالات البيوكيميائية في الأطفال الذين

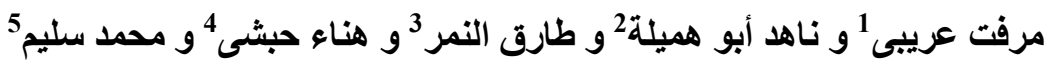

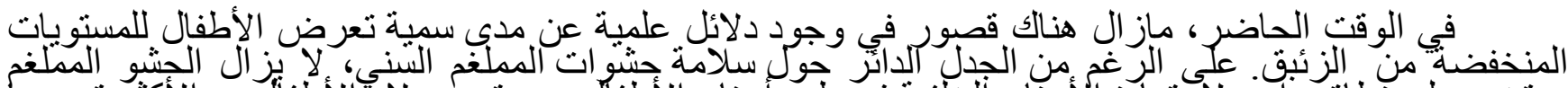

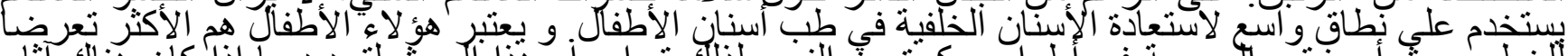

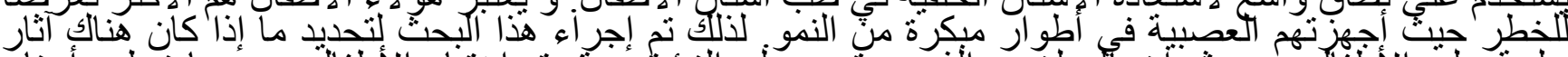

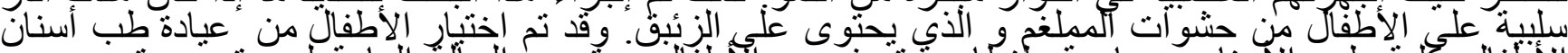

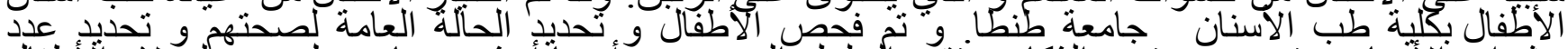

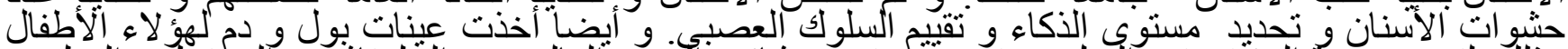

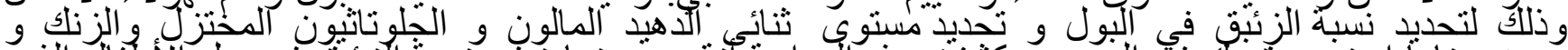

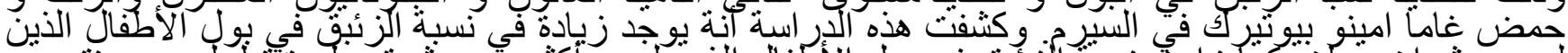

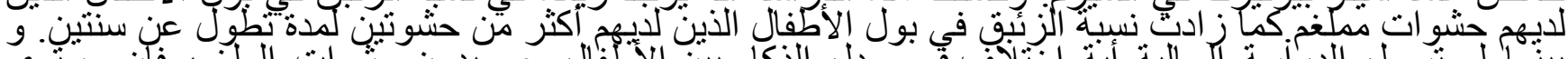

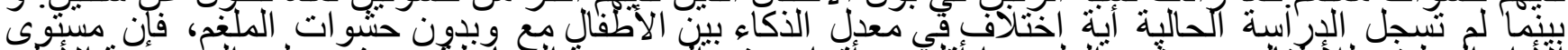

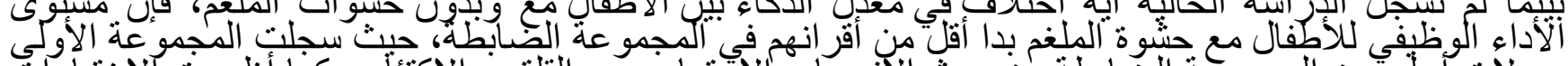

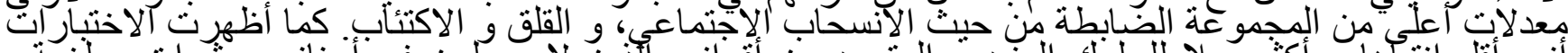

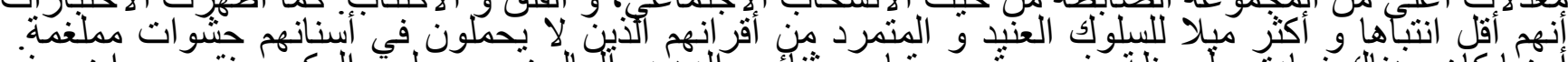

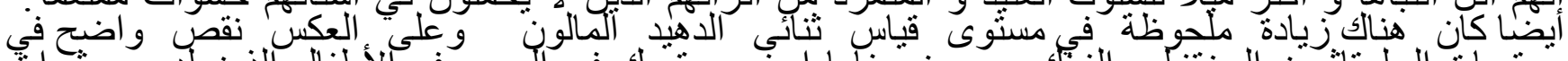

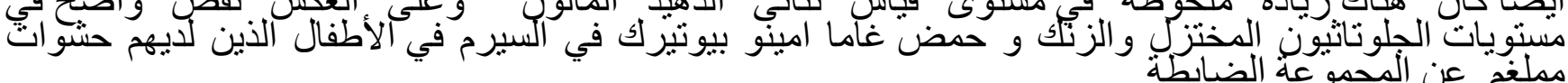

\begin{tabular}{|c|c|}
\hline \multirow[t]{4}{*}{ جامعة طنطا } & I قسم الطب الشرعي و السمو الإكلينيكية كلية الطب \\
\hline & 2 قسم أسنان الأطفال كلية الأسنان جامعة طنطا \\
\hline & 3 قسم الفيزياء كلية العلوم جامعة طنطا \\
\hline & 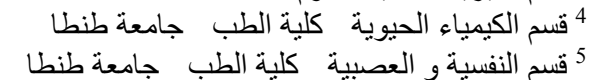 \\
\hline
\end{tabular}

